\title{
Elazığ İli Tıbbi Atık Yönetim Sisteminin Değerlendirilmesi ve Mali Sürdürülebilirlik
}

\author{
Nilüfer NACAR KOÇER ${ }^{1}$, Meltem GÖZEGİR ${ }^{2 *}$ \\ Fırat Üniversitesi, Çevre Mühendisliği Bölümü, Elazı ̆
}

\begin{abstract}
$\ddot{O} \mathbf{z}$
Nüfus artışı ve sanayileşme ile birlikte hasta sayısı, hastane sayısı ve ilaç kullanımı artmakta buna paralel olarak da tıbbi atıkların miktarı hızlı bir şekilde artarak çevre sorunu haline gelmektedir. Tıbbî atıklar, evsel atıklardan ayrı toplanması ve uygun şekilde giderilmesi gereken özel atıklardır. Ülkemizde tıbbî atıklar, 25.01.2017 tarih ve 29959 sayılı Resmi Gazete'de yayımlanarak yürürlüğe girmiş olan "Tıbbî Atıkların Kontrolü Yönetmeliği”" hükümleri çerçevesinde yönetilmektedir.

Yapılan bu çalışmada; Elazığ İli'nde toplanan ve sterilize edilen tıbbi atıkların zamansal değişimleri incelenerek, kişi başına üretilen tıbbî atık miktarları hesaplanmış ve uygulanan yönetim sisteminin değerlendirmesi yapılmıştır. Buna göre; 2016 yılı için Elazığ İli’nde oluşan tıbbî atık miktarı 0,68 kg/gün/yatak ve 0,74 kg/gün/yatak tespit edilmiştir.
\end{abstract}

Anahtar kelimeler: Elazığ İli, Sterilizasyon, Tıbbi Atık, Nüfus.

\section{Evaluation of Medical Waste Management System in Elazı̆̆ City and Financial Sustainability}

\begin{abstract}
Along with population growth and industrialization, the number of patients, the number of hospitals and the use of medicines are increasing, and the amount of medical wastes increases rapidly and becomes an environmental problem. Medical wastes are to be collected in different ways according as household wastes, and eliminated with specifically designed procedures. The medical wastes in our country have been managed according to the "Regulation of Medical Wastes" enacted and administrated in the Official Bulletin 29959 on January 25, 2017.

In this study, the temporal changes of medical wastes collected and sterilized in Elazı̆̆ province were examined and the amount of medical waste generated per person was calculated and the applied management system was evaluated. According to this; The amount of medical waste generated in Elazı̆ Province for the year 2016 was $0.68 \mathrm{~kg} /$ day / bed and $0.74 \mathrm{~kg} /$ day / bed.
\end{abstract}

Keywords: Elazı̆̆ City, Medical Waste, Sterilization, Population.

\section{Giriş}

Türkiye'de son yıllarda değişen insan aktiviteleri ve yaşam tarzları farklı tür atıkların büyük miktarlarda oluşmasına neden olmaktadır.

Atıklar ekosistemdeki tüm canlıların yaşamlarını tehdit ettiği gibi aynı zamanda suda, havada ve toprakta kalıcı özellik göstererek ekosistemdeki dengeyi bozabilen atıklardır [1]. Dünyada ve ülkemizde tüm atık miktarlarında olduğu gibi tıbbi atık miktarında da sürekli artış meydana gelmektedir. Tıbbi atıkların taşıdığı hastalık yapıcı mikroorganizmalar doğrudan bulaşabildikleri gibi su kaynaklarına da kontamine olmaları nedeniyle halk sağlığında önemli sorunlar meydana getirmekte ve ülkemiz için de

*Sorumlu yazar: mltmgozegir@gmail.com

Geliş Tarihi: 30/11/2017 Kabul Tarihi: 22/02/2018 
ciddi problemlere neden olmaktadır. Bu problemlerin doğal çevresel ortamlarda kısa ve uzun vadede meydana getirdiği etkilerinden dolayı konu üzerinde titizlilikle durulmasını gerekmektedir.

Bu tür atıklar zararlı ve tehlikeli atık sınıfına girmekte ve bu atıkların üretiminden, taşıma, depolama ve bertarafına kadar olan süreçlerde özel önlemler alınarak bertaraf edilmesi gerekmektedir [2]. Sağlık kurumlarında oluşan tıbbi atıkların üretildikleri yerlerde toplanması, taşınması, geçici depolanarak bertaraf edilmesi ile ilgili esasları düzenleyen Tıbbi Atıkların Kontrolü Yönetmeliği 25/01/2017 tarihli ve 29959 sayılı Resmi Gazete'de yayınlanarak yürürlüğe girmiştir. Bu yönetmelikte tıbbi atıkların bertaraf edilme yöntemleri yeniden düzenlenerek bu atıklar için alternatif bertaraf teknolojileri hakkında düzenlemeler yapılmıştır. Bu düzenlemeye göre; enfeksiyon yapıcı atıklar ile kesici-delici atıklar sınıfina giren tıbbi atıklar yakılarak, sterilizasyon işlemi uygulanarak veya düzenli depolanarak zararsız hale getirilmektedir. Bu bertaraf yöntemleri tek uygulanabildiği gibi birkaçı aynı anda uygulanabilir. Zararsız hale getirilen atıklar, 26/03/2010 tarihli ve 27533 sayılı Resmî Gazete'de yayımlanan Atıkların Düzenli Depolanmasına Dair Yönetmelikte belirtildiği gibi düzenli depolama sahalarında bertaraf edilmesi gereklidir [3].

\subsection{Tıbbi Atıkların Tanımı ve Tıbbi Atık Üreten Sağlık Kuruluşları}

Tıbbi Atıkların Kontrolü Yönetmeliği'ne göre; kesici delici atıklar, patolojik atıklar ve enfeksiyon yapıcı atıkların tümü tıbbi atık olarak ifade edilmektedir [3]. Faaliyetleri sonucu atık oluşumuna sebep olan sağlık kurumları büyük, orta ve küçük olmak üzere üç ana başlık altında toplanabilmektedir. Bu tıbbi atık üreten sağlık kuruluşları Tablo 1.1'de verilmiştir.

Tablo 1.1.Tıbbi Atık Üreten Sağlık Kuruluşları [4]

\begin{tabular}{|c|c|c|}
\hline $\begin{array}{c}\text { BÜYÜK MIKTARDA } \\
\text { ATIK ÜRETILEN } \\
\text { SAĞLIK } \\
\text { KURULUŞLARI }\end{array}$ & $\begin{array}{c}\text { ORTA MIKTARDA } \\
\text { ATIK ÜRETILEN } \\
\text { SAĞLIK KURULUŞLARI }\end{array}$ & $\begin{array}{c}\text { KÜÇÜK MIKTARDA } \\
\text { ATIK ÜRETİLEN } \\
\text { SAĞLIK KURULUŞLARI }\end{array}$ \\
\hline $\begin{array}{l}\text { 1. Üniversite Hastaneleri } \\
\text { ve } \\
\text { Poliklinikleri, } \\
\text { 2. Genel Amaçlı } \\
\text { Hastaneler ve } \\
\text { Poliklinikleri, } \\
\text { 3. Kadın-Doğum } \\
\text { Hastaneleri ve } \\
\text { Poliklinikleri, } \\
\text { 4. Askeri Hastaneler } \\
\text { ve } \\
\text { Poliklinikleri, }\end{array}$ & $\begin{array}{l}\text { 1. Sağlık Merkezleri, Tıp Merkezleri, } \\
\text { Dispanserler, } \\
\text { 2. Ayakta Tedavi Yapan Merkezler, } \\
\text { 3. Otopsi Merkezleri ve Morglar } \\
\text { 4. Hayvanlar Üzerinde Araştırma ve } \\
\text { Deney Gerçekleştiren Kuruluşlar, } \\
\text { 5. Bakımevleri ve Huzurevleri, } \\
\text { 6. Biyomedikal Şirketler ve } \\
\text { Tibbi Laboratuarlar, } \\
\text { 7. Hayvan Hastaneleri, } \\
\text { 8. Kan Bankaları ve Transfüzyon } \\
\text { Merkezleri, } \\
\text { 9. İlk Yardım ve Acil Yardım } \\
\text { Merkezleri, } \\
\text { 10. Diyaliz Merkezleri, } \\
\text { 11. Rehabilitasyon Merkezleri, } \\
\text { 12. Biyoteknoloji Enstitüleri ve } \\
\text { Laboratuvarları, } \\
\text { 13. Tıbbi Araştırma Merkezleri. }\end{array}$ & $\begin{array}{l}\text { 1. Sağlık Hizmeti Verilen Diğer } \\
\text { Birimler } \\
\text { (Doktor Muayenehaneleri, ve } \\
\text { Ağı Sağllğı Diş Muayenehaneleri } \\
\text { ve Benzerleri), } \\
\text { 2. Veteriner Muayenehaneleri, } \\
\text { 3. Akapunktur Merkezleri, } \\
\text { 4. Fizik Tedavi Yapan Üniteler, } \\
\text { 5. Evde Yapılan Tedavi ve } \\
\text { Hemşire Hizmetleri, } \\
\text { 6. Güzellik, Dövme Merkezleri ve } \\
\text { Kulak Delme Birimleri, } \\
\text { 7. Eczaneler, } \\
\text { 8. Ambulans Hizmetleri Veren } \\
\text { Birimler, }\end{array}$ \\
\hline
\end{tabular}




\subsection{Tıbbi Atık Türleri}

Sağlık kuruluşlarında meydana gelen tıbbi atıkların tümü hastane atıkları olarak tanımlanmakta ve çevre kirliliğine neden olan etkenlerin başında gelmektedir. Bu tür atıklar hastalar, hastane çalışanları ve toplum sağlığı açısından önemli risk oluşturmaktadır [5]. Hastane atıkları kendi içerisinde kategorilere ayrılmıştır. Bu sınıflandırma aşağıdaki gibi yapılmaktadır [3, 4, 6, 7,8].

Enfeksiyöz Atık: Enfeksiyon yapıcı etkenleri taşıdığı bilinen kan ve kan ürünleri olmak üzere her türlü insan dokuları, vücut sıvıları ile organları, otopsi materyali, anatomik parçalar, veterinerlik gibi hizmetlerinden kaynaklanan atıklardır.

Patolojik Atık : Cerrahi müdahale, anatomi, otopsi veya patolojik çalışmalar sonucu ortaya çıkan organlar, dokular, vücut sıvıları, vücut parçaları vb. gibi atıklardır.

Kesici Delici Atıklar : Enjektörler, tıbbi girişim iğneleri, bıçak, bisturi, cerrahi iğneler, serum seti iğneleri, kırık cam, ampul, lam-lamel, kırılmış cam tüp, biyopsi iğneleri, ve petri kapları gibi atıkların tümünü içerir.

Farmasotik Atıklar : Kullanım süresi dolmuş, ambalajı bozulmuş, ve kontamine olmuş ilaçlar, serumlar, aşılar ve farmasötik ürünler ve bunların artıklarından oluşmaktadır.

Genotoksik Atıklar : Hücre DNA'sı üzerinde değişikliğe neden olan, kanser tedavisinde kullanılan ürünler ve radyoaktif madde içeren atıkları içermektedir. Çok tehlikeli atıklardır ve kanserojenik özellik taşımaktadır.

Kimyasal Atıklar : Ünitelerde teşhis, tedavi gibi tıbbi alanlarda kullanılan ve çeşitli etkiler sonucu çevre ve insan sağ lı̆̆ açısından zararlı olma özelliği gösteren tehlikeli ve tehlikesiz türleri olan kimyasal maddelerden oluşan katı, sıvı veya gaz olan atıklardır.

Ağır Metal İçeren Atıklar : Sağlık birimlerinde tedavi, teşhis veya deneysel araştırmalar sonucu tıbbi alandaki çalışmalarda kullanılan alet ve ekipmanların ihtiva ettiği kadmiyum, cıva ve kurşun içeren atıklardır.

Basınçı Kaplar : Ünitelerde tanı, tedavi veya deney yapılan araştırma merkezlerinde kullanılan gazları içinde bulunduran tüp gibi kapları içermektedir.

Radyoaktif Atıklar : Radyoterapi ve laboratuar çalışmalarından kullanılmayan akışkanlar; temas etmiş cam eşyalar vb gibi atıkları içermektedir.

\subsection{Tıbbi Atık Kompozisyonu ve Tıbbi Atık Üretim Miktarı}

Tıbbi atıklar insan sağlığı açısından büyük tehlike oluşturmakla birlikte bu atıkların bir kısmı da tehlikeli değildir. Dünya Sağlık Teşkilatı'nın tıbbi atık kompozisyonu verilerine göre; \%15'ini patolojik ve enfekte atıklar, \%80'nini evsel nitelikli genel atıklar, \%1'ini kesici-delici atıklar, \%3'ünü kimyasal ve farmasötik atıklar, \%1'ini de piller, radyoaktif atıklar, basınçlı kaplar, kırık termometreler ve kullanılmış özel atıklar oluşturmaktadır [9].

Hastanelerde oluşan tıbbi atık miktarı ülkelerin gelişmişlik düzeyiyle paralellik göstermektedir. Tablo 1.2.'de ulusal gelir düzeyine göre oluşan tıbbi atık miktarları gösterilmiştir. Gelir düzeylerinin artmasıyla atık miktarının da arttığı görülmektedir [10]. Hastanelerdeki atık miktarları, kurumların atık yönetim sistemleri, hastanelerin özellikleri ve çeşitleri, kullanılan medikal malzemelerin yeniden kullanım oranları ve kurumlardaki günlük tedavi edilen hasta sayısı gibi değişik parametrelere bağlı olarak değişmektedir [11]. 
Tablo 1.2. Ulusal Gelir Düzeyine Göre Tıbbi Atık Üretimi Miktarları [12]

\begin{tabular}{|c|c|}
\hline ULUSAL GELİ DÜZEYİ SINIFLANDIRMASI & $\begin{array}{l}\text { YILLIK ATIK } \\
\text { ÜRETIMI, } \\
\text { kg kişi }^{-1}\end{array}$ \\
\hline $\begin{array}{l}\text { YÜKSEK GELİRLI ÜLKELERE AİT ATIKLAR } \\
\text { - Tüm tıbbi atıklar } \\
\text { - Tehlikeli tıbbi atıklar }\end{array}$ & $\begin{array}{l}1.1-12.0 \\
0.4-5.5\end{array}$ \\
\hline $\begin{array}{l}\text { ORTA GELIRLI ÜLKELERE AİT ATIKLAR } \\
\text { - Tüm tıbbi atıklar } \\
\text { - Tehlikeli tıbbi atıklar }\end{array}$ & $\begin{array}{l}0.8-6.0 \\
0.3-0.4\end{array}$ \\
\hline $\begin{array}{l}\text { DÜŞÜK GELİRLİ ÜLKELERE AİT ATIKLAR } \\
\text { - Tüm tıbbi atıklar }\end{array}$ & $0.5-3.0$ \\
\hline
\end{tabular}

\subsection{Tıbbi Atık Yönetimi}

Sağlık birimlerinde oluşan tıbbi atıkların yönetimi, tıbbi atıkların oluşumundan bertarafına kadar geçen süreci kapsamaktadır. Sağlık birimlerinde tıbbi atık yönetiminin başarılı bir şekilde uygulanabilmesi için Tıbbi Atık Yönetim Stratejilerinin uygulanması gereklidir [13].

Atık yönetim stratejisinde temel amaç, insanların sağlığı ve çevreye zarar vermeden atıkların ekonomik olarak toplanması, ayrılması, tekrar kullanılması, geri dönüştürülmesi ve miktarlarının azaltılarak güvenli bir şekilde bertaraf edilmesini içermektedir [14]. İnsan ve çevre sağlığı açısından bakıldığında; insanların atık üretme konusunda hassas davranması, atık yönetim çalışmalarını uygulaması ve atık yönetimine katılım oranlarının artırılmasının sağlanması ile oluşabilecek riskler azaltılabilir [15].

Tıbbi atıklar enfeksiyon riski taşıdıklarından bu atıklardan kaynaklanabilecek tehlikelerde uygulanacak optimum atık yönetimi ile tehlikeli atık miktarı azaltılmalıdır. Günümüzde tıbbi atık üreten ülkelerin büyük bir k1smı atık yönetiminde en ekonomik yöntemleri tercih etmektedir [16].

\subsection{Tıbbi Atıkların Bertaraf Yöntemleri}

Tıbbi atıkların giderilmesindeki amaç, atıkların tehlike oluşturmayan maddelere dönüştürülerek çevre ve insan sağlığını korumaktır. Tıbbi atıklar için en çok kullanılan bertaraf yöntemleri; düzenli depolama, yakma, kimyasal dezenfeksiyon, otoklavlama, mikrodalga ve 1şınlama teknolojisi, enkapsülasyon ve sterilizasyondur [6].

\section{Materyal ve Metot}

\subsection{Elazı̆ğ Tıbbî Atık Yönetim Sistemi}

Elazığ İli'nde uygulanan Tıbbî Atık Yönetim Sistemi, belediye sınırları içerisinde bulunan tüm devlet hastaneleri, özel hastaneler, diyaliz merkezleri, aile sağlığı merkezleri, laboratuvarlar ve ilçe belediyelerinden kaynaklanan tüm tıbbî atıkların bertarafını içermektedir. Elazığ İli Belediye sınırları içerisinde kalan ve ilçe belediyelerinden kaynaklanan tıbbi atıklar, Tıbbî Atıkların Kontrolü Yönetmeliği kapsamı içerisinde tıbbi atıklar sağlık riski açısından insan ve çevre sağlığına zarar vermeden ayrı toplanması, taşınması ve işletmede olan tıbbî atık sterilizasyon tesisinde sterilize edildikten sonra katı atık depolama alanına aktarılarak bertaraf edilmesini amaçlamaktadır. Elazı $\breve{g}$ İli'nde devlet hastaneleri, özel hastaneler, diyaliz merkezleri, aile sağlı̆̆ merkezleri ve laboratuvarlardan kaynaklanan yıllara göre toplam tıbbi atık miktarları ve nüfusa göre kişi başına düşen tıbbi atık miktarı Tablo 2.1.'de verilmiştir. 
Tablo 2.1. Elazı̆̆ İli’nde Yıllara Göre Nüfusa Bağlı T1bbi Atık Miktarı $[17,18]$

\begin{tabular}{|c|c|c|c|}
\hline Yılar & $\begin{array}{c}\text { Elazı̆̆ İli } \\
\text { Nüfusu } \\
\text { (kişi) }\end{array}$ & $\begin{array}{c}\text { Tıbbi Atık } \\
\text { Miktarı } \\
\text { (ton) }\end{array}$ & $\begin{array}{c}\text { Tıbbi Atık } \\
\text { Miktarı } \\
\text { (ton/kişi) }\end{array}$ \\
\hline 2009 & 550.667 & 450 & 0.82 \\
2010 & 552.646 & 425 & 0.77 \\
2011 & 558.556 & 430 & 0.77 \\
2012 & 562.703 & 376 & 0.67 \\
2013 & 568.239 & 396 & 0.70 \\
2014 & 568.753 & 511 & 0.90 \\
2015 & 574.304 & 590 & 1.03 \\
2016 & 578.789 & 720 & 1.24 \\
\hline
\end{tabular}

Elazığ İli nüfusu ve oluşan tıbbi atık miktarları düşünüldüğünde; Tablo 2.1'de görüldüğü gibi yıllara göre paralel bir artış gözlenmektedir. Elazığ İli nüfusu 2009 yılında 550.667 iken 2016 yılında 578.789'a yükselmiş ve buna bağlı olarak kişi başına düşen tıbbi atık miktarı 2009 yılında 0,82 iken 2016 yılında 1,24 ton/kişi'ye ulaşmıştır. Tablo 2.1.'den de görüldüğü gibi nüfus 2009 yılından 2016 yılına kadar $\% 5,11$ artış gösterirken kişi başına düşen atık miktarı \%51,2'lik bir artış göstermiştir. Bu da yıl itibariyle hastalıkların ve hastaneye gidiş oranının arttığını göstermektedir.

\subsection{Etkin Yönetim Sisteminin Uygulanması}

Etkin yönetim sisteminin uygulanmasındaki amaç; oluşan tıbbi atıkların kaynaklarından bertarafına kadar olan süreç içerisinde kayıt ve kontrol altında tutulmasını sağlamaktadır. Bu amaç çerçevesinde Elazığ İli sınırları içerisinde bulunan toplam 12 sağlık kuruluşundan lisanslı araçlar ile toplanan tıbbi atıklar sterilizasyon ünitesinde sterilize edildikten sonra bertaraf alanına aktarılmaktadır. Elazı ğ sınırları içerisindeki il ve ilçelerden kaynaklanan tıbbi atık miktarları Tablo 2.2.'de verilmiştir $[18,19]$. Buna göre; 2016 yılı için bu sağlık kuruluşlarının toplam yatak kapasitesi yaklaşık 2.823 olup, toplamda yaklaşık aylık 57,4 ton tıbbi atık toplanmaktadır. Bu sağlık kuruluşlarına ilave olarak aile sağlığı merkezleri, laboratuvardan ve diğer kuruluşlardan gelen atıklar da eklendiğinde ortalama yaklaşı 60 ton civarında tıbbi atık toplandığı görülmektedir. En fazla tıbbi atık üreten sağlık kuruluşları Özel Doğu Anadolu Hastanesi, Palu ve Maden Devlet Hastaneleri, Özel Medicalpark Hastanesi, Karakoçan İlçe Devlet Hastanesi ve Elazığ Fırat Üniversitesi Hastanesi'dir. Elazığ Fırat Üniversitesi Hastanesi en fazla tıbbi atık miktarına sahip olmasına rağmen yataklardaki doluluk oranına bağlı kişi başına düşen atık miktarı düşmektedir. Elazığ İli Tibbî Atık yönetim sisteminin etkin uygulanabilmesi için oluşan atık miktarının bilinmesi gerekmektedir. 
Tablo 2.2. Elazığ İli’nde Bulunan Hastanelerden Kaynaklanan Tıbbi Atık Miktarları [18, 19]

\begin{tabular}{|c|c|c|c|c|}
\hline SIRA & HASTANE ADI & $\begin{array}{l}\text { YATAK } \\
\text { SAYISI } \\
\text { (adet) }\end{array}$ & $\begin{array}{c}\text { ORTALAMA } \\
\text { TIBBİ ATIK } \\
\text { MIKTARI } \\
\left(\text { ton ay }^{-1}\right)\end{array}$ & $\begin{array}{l}\text { TIBBİ ATIK } \\
\text { MİKTARI } \\
\left(\text { kg yatak. gün }^{-1}\right)\end{array}$ \\
\hline 1 & $\begin{array}{l}\text { Elazı̆ Fırat Üniversitesi } \\
\text { Hastanesiden }\end{array}$ & 880 & 24.5 & 0,93 \\
\hline 2 & $\begin{array}{l}\text { Elazı̆̆ Eğitim ve Araştırma } \\
\text { Hast. }\end{array}$ & 539 & 11.1 & 0,69 \\
\hline 3 & Elazığ Ruh Sağlığı Hastanesi & 510 & 1.2 & 0,08 \\
\hline 4 & $\begin{array}{l}\text { Elazı̆̆ Harput Devlet } \\
\text { Hastanesi }\end{array}$ & 317 & 3 & 0,32 \\
\hline 5 & Özel Medicalpark Hastanesi & 198 & 7 & 1,18 \\
\hline 6 & $\begin{array}{l}\text { Elazığ Deri ve Zührevi } \\
\text { Hastanesi }\end{array}$ & 125 & 1 & 0,27 \\
\hline 7 & Özel Doğu Anadolu Hastanesi & 75 & 4 & 1,78 \\
\hline 8 & Özel Hayat Hastanesi & 54 & 1.5 & 0,93 \\
\hline 9 & $\begin{array}{l}\text { Kovancilar İlçe Devlet } \\
\text { Hastanesi }\end{array}$ & 40 & 1.1 & 0,92 \\
\hline 10 & $\begin{array}{l}\text { Karakoçan İlçe Devlet } \\
\text { Hastanesi }\end{array}$ & 35 & 1 & 0,95 \\
\hline 11 & Maden İlçe Devlet Hastanesi & 25 & 1 & 1,30 \\
\hline 12 & Palu İlçe Devlet Hastanesi & 25 & 1 & 1,30 \\
\hline & T O P L A M & 2.823 & 57,4 & 0,68 \\
\hline
\end{tabular}

Elazığ İli'nde toplanan tıbbî atıklar, 2012 yılında faaliyete geçen sterilizasyon tesisinde sterilize edildikten sonra katı atık düzenli depolama sahasına aktarılmaktadır. Kurulan sterilizasyon tesisi 2.000 ton yıl ${ }^{-1}$ kapasitelidir. Elazığ İli sınırları içerisindeki tüm sağlık kuruluşlarından oluşan tıbbi atıklar özel tıbbi atık taşıma araçları ile toplanarak, sterilizasyon tesisinde sterilize edilmek üzere taşınmaktadır. Sterilizasyon tesisine getirilen tıbbi atıklar $+4^{\circ} \mathrm{C}$ 'nin altında soğutulmuş geçici atık depolarında biriktirilmektedir. Sterilizasyon tesisi hem Elazığ ili hem de çevre illerin tıbbi atıklarını sterilize edebilecek kapasiteye sahiptir [18, 20].

Tesiste biriktirilen atıklar el değmeden otoklava boşaltılmakta ve 200-250 kg civarındaki atık otoklavda her döngüde 1-1,5 saat işlem görmektedir. Sistem $138^{\circ} \mathrm{C}$ sıcaklık ve 3,8 bar basınç altında çalışmaktadır. Sistemdeki sterilizasyon kontrolü; tıbbi atıklar akredite laboratuvara gönderilerek yapılmaktadır. Tüm bu işlem el değmeden tam otomatik otomasyonla Şekil 2.2.'de görüldüğü gibi uygulanmaktadır. 

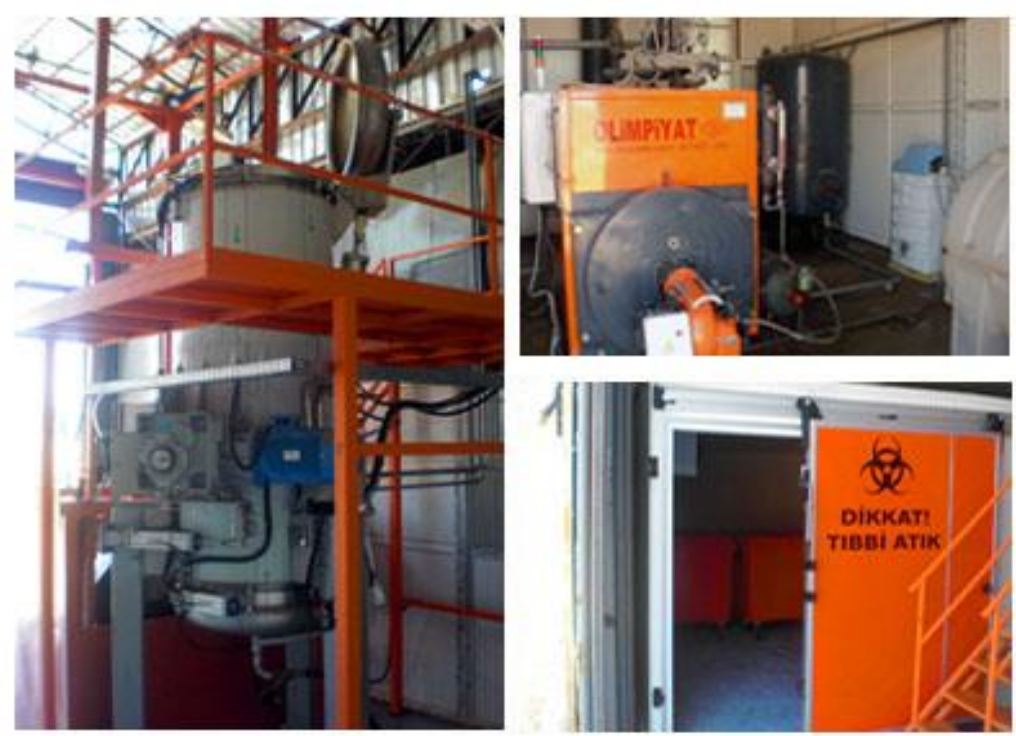

Şekil 2.2. Elazı ̆̆ İli Sterilizasyon Tesisi [18, 20]

Elazığ İli'nde 2016 yılı içinde toplanan tıbbi atıklar yaklaşık haftada 15 ton civarındadır. Düzenli olarak toplanacak atık miktarı yılda yaklaşık 680-720 ton civarındadır. Sterilizasyon işlemi sonucunda çıkan steril olmuş atıklar katı atık düzenli depolama sahasında depolanmaktadır [18].

\section{Bulgular ve Tartışma}

\subsection{Mali Sürdürülebilirlik}

Yönetim sisteminin en etkin göstergelerinden birisi atık bertarafı için gerekli olan finans kaynağının sürekliliğinin sağlanmasıdır. Süreklilik sağlanmak için gerekli mali kaynak tıbbi atık üreticileridir. Üreticilerin üretmiş oldukları tıbbi atık miktarına göre, ödemek zorunda oldukları bir bedel bulunmaktadır. Uygulanacak yönetim sistemi ve yapılacak eğitim çalışmaları ile sağlık kurumlarının üretmiş oldukları tıbbi atıkların tıbbî atık özelliğinde olmayan atıklarla karışması önlenerek, atık miktarının azaltılması sağlanmakta ve ödenmesi gereken atık bedelinde de azalma olmaktadır.

Elazığ İl Mahalli Çevre Kurulu tarafından belirlenen tıbbi atık sterilizasyon bedeli 2015 y1lında $\mathrm{kg}$ başına 2.40 TL (KDV hariç)'dir. Tıbbi atık sterilizasyon bedeli 2016 yılı için kg başına 2.60 TL (KDV hariç) ve 2017 yılı için de 2.70 TL (KDV hariç) olarak belirlenmiştir [18]. Elazı̆̆ da 2016 yılı aylık ortalama tıbbi atık miktarı ve ortalama sterilizasyon bedeli Tablo 3.1.'de hesaplanarak verilmiştir.

Tablo 3.1. Elazığ İli 2016 Yılı Aylık Sterilizasyon Bedeli [18]

\begin{tabular}{|l|c|c||}
\hline AYLAR & $\begin{array}{c}\text { ORTALAMA } \\
\text { TIBBİ ATIK } \\
\text { MIKTARI, } \\
\text { Ton }\end{array}$ & $\begin{array}{c}\text { ORTALAMA } \\
\text { STERILIZIZASYON } \\
\text { BEDELI, TL } \\
\text { (KDV HARIÇ) }\end{array}$ \\
\hline Ocak & 59.99 & 155.984 \\
\hline Şubat & 62.84 & 163.379 \\
\hline Mart & 61.10 & 158.870 \\
\hline Nisan & 58.12 & 151.109 \\
\hline Mayıs & 62.20 & 161.720 \\
\hline Haziran & 58.04 & 150.896 \\
\hline
\end{tabular}




\begin{tabular}{|l|c|c||}
\hline Temmuz & 58.90 & 153.140 \\
\hline Ağustos & 58.12 & 151.109 \\
\hline Eylül & 57.53 & 149.583 \\
\hline Ekim & 60.83 & 158.145 \\
\hline Kasım & 62.35 & 162.120 \\
\hline Aralık & 61.92 & 160.989 \\
\hline TOPLAM & 721.64 & 1.877 .044 \\
\hline
\end{tabular}

Elazığ İli sterilizasyon tesisinde 2016 y1lı için $1 \mathrm{~kg}$ tıbbi atığın sterilizasyon bedeli 2,60 TL (KDV hariç) olarak belirlendiği göz önüne alınırsa; sterilizasyon ünitesinde 2016 yılında ortalama 722 ton tıbbi atık sterilize edilmiş ve Tablo 3.1.'de görüldüğü gibi sterilizasyon bedeli de yıllık 1.877.044 TL + KDV olarak hesaplanmıştır.

Ortalama tıbbi atık miktarına bağlı olarak en fazla atık Şubat ayında 62,84 ton, en az tıbbi atık ise Eylül ayında 57,53 ton toplanarak sterilize edilmiştir. $\mathrm{Bu}$ verilere göre kişi başına düşen tıbbi atık miktarı

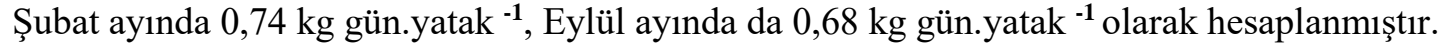

\section{Sonuç ve Öneriler}

Ülkemizde tıbbi atık uygulamalarının başarılı bir şekilde yürütülebilmesi için tıbbi atıklara ait düzenlenmiş olan yönetmelik hükümleri uygulanmaktadır. Bu çerçevede mevcut şartlar göz önünde bulundurularak, tıbbi atık sorumlularının yetki ve görevleri detaylı bir şekilde belirlenerek, tıbbi atıklarla ilgili sorumlu firma personeli ve kurumlar için yeterlik belgesi ya da sertifika alma zorunluluğu getirilmelidir. Yapılacak eğitimler, sadece tıbbi atıklar için değil, çevre üzerinde olumsuz etkileri olan diğer atıklar için de uygulanmalı ve oluşturabileceği riskler konusunda halk arasında farkındalık oluşturulması sağlanmalıdır.

Yapılan çalışmada; Elazı̆̆ İli'nde tıbbi atıklarla ilgili tespit edilen araştırma verileri doğrultusunda, envanter çalışması yapılarak, uygulanmakta olan durum ortaya konulmuştur Tıbbi atık yönetimi konusunda hem toplum hem de sağlık kuruluşlarında çalışan sorumlu tıbbi atık çalışanları için sürekli olarak bilinçlendirme çalışmaları yapılarak, eğitim programları düzenlenmelidir. Elazığ'da hastanelerde yapılan çalışmalar sırasında, sağlık kuruluşlarında üretilen tıbbi atık miktarlarının kurum yetkililerince yeterince bilinmediği, tıbbi atıkların yönetimi ve giderilmesi konularında yönetmelikte belirtilen koşulların asgari şartlarda gerçekleştirilmesine çalışıldığı dikkat çekmektedir. Tıbbi atıkların yönetmelik hükümleri çerçevesinde toplanmaması sonucunda tıbbi atık personelinin değişik sağlık problemleri ile karşı karşıya kalacağı unutulmamalıdır. Yetkili personel tarafından; toplama ve taşıma işleminin düzenli ve güvenilir bir şekilde gerçekleştirilmesi, tıbbî atıklar için metal ve radyoaktivite ölçümlerinin sürekli yapılması; on-line izleme yapabilen bilgisayar programları ile atıkların ünitelerde tartımının yapılarak, barkotlama işleminin uygulanması, atıkların kaynaktan itibaren geçtiği süreçlerin takip edilerek gerçekleştirilmesi gereklidir. 


\section{Kaynaklar}

1. Henry J.G., Heinke G.W. 1996. Environmental Science and Engineering. Second Edition, 778 pp, Prentice Hall, Inc., New Jersey, ABD.

2. Baylan A. 2009. Tııbi Atıkların Bertarafı Üzerine Çalışma Edirne Örneği. Namık Kemal Üniversitesi, Fen Bilimleri Enstitüsü, Yüksek Lisans Tezi.

3. Tıbbi Atıkların Kontrolü Yönetmeliği. 2017. Çevre ve Şehircilik Bakanlığı, 29959 sayılı Resmi Gazete, 25 Ocak 2017.

4. Tıbbi Atıkların Kontrolü Yönetmeliği. 2005. Çevre ve Orman Bakanlı̆̆ı, 25883 sayılı Resmi Gazete.

5. Rahman S., Açık Y., Gülbayrak C., Erhan D., Nazlıer K., Deveci S.E. 2009. Sağlık Kuruluşlarının Tıbbi Atık Toplama, Depolama ve Bertaraf Etme Yöntemleri, Fırat Sağlık Hizmetleri Dergisi, Cilt:4, Say1:11.

6. Prüss A.-Giroult, E.-Rushbook, P. 1999. Safe Management of Wastes from Health-care Activities. Geneva: World Health Organization: 2-8.

7. WHO. 1999. Safe Management of Wastes from Healt-Care Activities, Ceneve.

8. WHO. 2000. Suggested Guiding Principles and Practices for Sound Management of Hazardous Hospital Waste, New Delhi.

9. WHO. 2000. MDI/EIP Marketing and Dissemination, Wastes from Health Care Activities, Genova.

10.EPA. 1990. Operation and Maintenance of Hospital Medical Waste Incerator, EPA/625/689/024, Çevre Koruma Ajansı, Ohio.

11.Dündar E. 2010. Hastane Atıklarının Yönetiminde Geri Kazanılabilir Atık Miktarlarının Tesbiti ve Ekonomik Değeri Ankara Örneği. Gazi Üniversitesi, Fen Bilimleri Enstitüsü, Yüksek Lisans Tezi, Ankara.

12. AB Komisyonu. 1995. Ulusal Gelir Düzeyine Gore T1bbi Atık Üretimi.

13.Esmen C., Varınca K.B., Şengil A.S. 2008. Tıbbi Atık Yönetiminde Yeni Bir Model Örneği, ÇESKO 2008.

14.Varınca K.B., Esmen C., Gönüllü M.T. 2009. Bursa İli Tıbbî Atık Yönetim Sistemi Performans Değerlendirmesi, TÜRKAY 2009, Türkiye'de Kat1 Atık Yönetimi Sempozyumu, YTÜ, 15-17 Haziran 2009, İstanbul.

15.Özerol İ.H. 2005. Tıbbi Atık Stratejileri Nelerdir? EN/ISO Normları Nelerdir? Avrupa'da Birlik? ABD’nin Yaklaşımı? Ülkemizde Durum?, İnönü Üniversitesi Tıp Fakültesi, Mikrobiyoloji ve Klinik Mikrobiyoloji Anabilim Dal, Malatya.

16.Kuhling J.G. 2002. Hastane Atıkları, Dünya Katı Atık Çevre Kongresi, Boğaziçi Üniversitesi, İstanbul.

17. Türkiye İstatistik Kurumu (TÜİK). 2016. Adrese Dayalı Nüfus Kayıt Sistemi (ADNKS) Veritabanı, http://tuikapp.tuik.gov.tr/adnksdagitapp/adnks.zul.

18. Elazığ Belediyesi. 2017. Çevre Koruma ve Kontrol Müdürlüğü, Tıbbi Atık Sterilizasyon Birimi. 
19. www.tdms.saglik.gov.tr

20. ERA Çevre Teknolojileri. http://www.eracevre.com/projeler/biten-projeler/elazig-tibbi-atiksterilizasyon-tesis. 